ment. This circumstance, in conjunction with the movement commenced in the College of Surgeons, renders it incumbent axpon all medical men to give some little attention to medical politics. Even those (few, we would hope, in number) who pursue the profession as a trade, are bound, from motives of self-interest, to look to the course and progress of medical legislation. The patriotic medical man will, from higher motives, give that attention to this momentous subject which it deserves. We abominate the prolongation of medical agitation, but we have long felt convinced that medical agitation can never cease, until a comprehensive legislation, in accordance with the spirit of the age, and acceptable to the entire profession, has been framed and carried into operation. Let the medical practitioners of this great country put their shoulders at once to the wheel, and finish the matter as they might well do during the present year. Better one year of sharp work and a satisfactory conclusion, than the long delay and the tedious dragging on of the Medical Reform question through future years. Once settled, science would advance in an accelerated ratio, and every material interest of the profession would be promoted.

There is one class of influential bodies which has never taken any part in the Medical Reform question, but which is eminently fitted to do so with great benefit and effect. We allude to the staff of the various medical colleges and schools, both of London and the counties. The corporations have been active enough, and so have various influential associations, but the profession has never heard the teachers of the rising generation of medical men speak out upon this matter. Doubtless few, if any, would be more calculated to give apinions of weight and worth than this body of gentlemen. Every element in the profession should contribute something towards its political and social advancement in the present position of things, and it would give us the most sincere pleasure if some of the greater educational institutions would pronounce their opinion upon the matters now agitating the profession.

THe great difficulties, confessedly, to the arrangement of the College of Surgeons in such a way as shall be perfectly satisfactory for the future to the surgeons in general practice, are, the proper recognition of the general practice of Medicine and Obstetrics in alliance with that of surgery, and the making due provision for the future education and examination of the general surgeon in these branches of medicine. The surgeon in general practice dislikes Apothecaries' Hall; a new college is seen to be a great grievance; and the College of Physicians long ago repudiated the general practitioner. Such being the case, we would propose a plan which, in the event of the refusal of the College of Surgeons to form an examining board in Medicine and Obstetrics, seems to us more free from objection than any other which suggests itself.

During the past year the Crown has conferred on the University of London a supplemental charter, one of the provisions of which is as follows:-

"That the Chancellor, Vice-Chancellor, and Fellows, shall have power, after examination, to grant certificates of profi. ciency in such branches of knowledge as they shall from time to time determine, by regulations made according to the Foundation Charter. And that, in addition to the examina tions of candidates for degrees, the Chancellor, Vice-Chancellor, and Fellows, may cause to be held, from time to time, examiuations of persons who shall have prosecuted the study. of such branches of knowledge, and shall be candidates for certificates of proficiency. And may make provision for classifying the candidates according to their relative degrees of proficiency, by the certificates, published lists, or otherwise."

In the orginal Charter of the University of London, the power of granting degrees in Arts, Laws, and Medicine only, was conferred upon the plan of the elder Universities. But the spread of modern science has created new departments of knowledge, wholly unknown and unrecognised by the ancient academies. It was felt by the Government, and this University, that in geology, geography, zoology, botany, engineering, and many other sections of science, a great stimulus would be given if University examinations and certificates of proficiency were attainable. This was one of the objects con templated in the amended Charter, from which we have quoted, but its administration and extension within the above spirit of course rests with the Senate of the University.

What we would suggest is this: that the examiners of the University of London, who are confessedly most highly fitted for such a duty, should be constituted by the Senate to examine in Medicine, Surgery, and Midwifery, in harmony with the examining board of the College of Surgeons, which may be allowed to give its chief attention to anatomy and surgery, and that the Certificate of proficiency of the University of London should take the place of the Licence of the Apothe caries' Society in the qualification of the general surgeon. We foresee manifold advantages arising from such an arrangement if the College should decline to examine in medicine and obstetrics. The transfer of the general practitioner from any connexion with the Apothecaries' Society to the Uni. versity of London would materially advance the rank of the most numerous and important of all the branches of the profession. We will not enter into any further discussion respecting this matter at the present time, because we trust the College of Surgeons may undertake examinations in medicine and midwifery as well as in surgery; but failing this, we should consider the proposition we have now sketched at one of the highest importance.

\section{THE ROYAL COLLEGE OF SURGEONS.}

ON Wednesday, the 19th ultimo, the deputation appointed at the Conference held on Tuesday, the 20th Nov., attended at the Royal College of Surgeons, where they were received by Mr. GreEn, the President of the Council, and by Mr. Arnom? and Mr. Sovth, the Vice-Presidents.

Mr. Clifros, the chairman of the meeting, held on the 20th Nov., stated, that a conference of members of the Reform Medical Associations had been convened by the National In: stitute, with a view to ascertain the opinions and objects of the various medical associations, and for the purpose of creating a unity of feeling and action in the profession, in the hope, and with an anxious desire, of settling the long-agitated question of medical reform. At that conference a resolution was passed, to the effect that a deputation should wait upon the Council of the College of Surgeons, to learn whether the Council were disposed to make such alterations in the constitution of the College as would be acceptable to the profession generally, and as would cause the College to be acknowledged and regarded as the "Head and Home" of the members at large. The deputation attended the Council in no unfriendly spirit, and he hoped the answer they might receive would diffuse a feeling of satisfaction throughont all ranks of the profession. The members of the College, consisting of many thousands of practitioners, felt that they had been grievonsly injured by the Charter of 1843 , and the conference and 
leputation hoped that they woul $d$ not profitlessly seek for relress.

Mr. Botrominex next addressed the president and vice-preidents, and said,-Gentlemen, you have already been informed y Mr. Clifton, that a conference was held in November, for ihe purpose of discussing the various grievances under which he members of the medical profession labour, but more par icularly those arising from the Charter of the College of Surreons of 1843. The object of the conference was, as has been sorrectly stated, to ascertain the various views and opinions which are held by the different medical reform associations, with the hope of adjusting any differences which might be ound to exist, and of creating a combined system of action hroughout the profession. Various were the opinions exoressed at the conference; and amongst other things, it was lecided that a "deputation" should apply to the Council of his College for an interview, the object bcing to ascertain rom the Council whether there be any objection to state what tre the changes which it is intended to make in the existing Tharter. That deputation is now before you, and we are mxious to learn-first, whether it be your intention to apply o the Crown for a new Charter; and secondly, if so, what are he leading provisions you are desirous it should contain. We leem it to be exceedingly important at this time to ascertain low far the proposed changes would accord with the views ind feelings of the profession generally. Allow me to remark, as chairman of the "Committee of Associated Surgeons of England," that it is the ardent and almost the unanimous desire of the provincial surgeons, by every means in their power, to uphold and maintain the dignity and reputation of his College. They feel most anxious to obtain a just and conourable position in this celebrated institution. It is their llma mater, and they wish it to be distinctly understood by the Council that they are decidedly opposed to the establishment of another College of Surgeons. They would regard such an event as a calamity; and as the Council have the power of wverting it, they sincerely hope that its authority will be exrcised in such a manner as to render such an establishment wholly unnecessary. They feel that this can only be done by rendering a new Charter, suitable to the altered circumstances of the members and the profession. They hope and believe hat the Council will not be influenced by predilections or past Jecisions, but that they will take a dispassionate view of the whole question. The members of the College consider that hey were most grievously injured by the Charter of 1843 ; and that by that legal instrument they were most wrongfully thrust into an inferior position. That many who, by nomination, first obtained the distinction of the "Fellowship" had not signalized themselves by their labours in either medicine or surgery; and that they were appointed without the least regard to their scientific attainments or to their standing in the profession. The diplomas of some of them were of a very recent date; yet many venerable members of the College, who had, by their labours, contributed to the advancement of the science of surgery, had the mortification of finding themselves displaced from their legitimate position in the College by persons who were far their juniors in years, and who had only ust previously obtained their diplomas. This wrong was, and is, severely felt. No adequate and sufficient remedy can now be found for the sinarting injury that was then inflicted. The members of the College hope that they are not influenced on this question by selfish considerations; and they wonld receive a new Charter, constructed on a just and liberal basis, as an offering from the Council of the highest possible value. The members desire to see the Royal College of Surgeons of Eng. land cherished, beloved, and respected, as the chief surgical and medical institution of the United Kingdom.

At the conclusion of Mr. Bottomley's address, the President was about to make some remarks, when $\mathbf{M r}$. Clifton observed that Mr. Bottomley had some "Suggestions" to submit to the Gouncil. Mr. Bottomley then stated, that if the President had any remarks to offer, he should be much pleased to hear them before he read the "suggestions." Mr. Green replied that he should like to hear the suggestions first. They were then read by Mr. Bottomley, as follows:-

SUGGESTIONS FOR AN AMIENDED CHARTER.

1. That surgeons engaged in "general practice" shall not be excluded from the Council.

: 2. That a majority of the Council may consist of gentlemen who are not engaged in the practice of midwifery or pharmacy.

3. That one-third of the Council shall retire every year, and je eligible for re-election after the expiration of one year.
4. That one-third of the Court of Examiners shall retire every year, and shali be eligible for re-election after the expiration of one year.

5. That the Council shall be elected by the fellows.

6. That the Court of Examiners shall be appointed by the Council.

7. That the fellows shall obtain their diplomas by examination and by election.

8. That members of the College of ten years' standing, if they do not keep open shops, or carry on a retail trade, shall be eligible for election as fellows.

9. That the members of the College shall be the electors of the fellows.

10. That the members shall, on receiving their diplomas, be at once entitled to exercise the franchise in the election of the fellows.

11. That the election of the fellows from amongst the members of ten years' standing and upwards shall take place yearly.

12. That the elections of the Council and fellows shall be conducted by balloting-papers, transmitted through the postoffice to the places of residence of the fellows and members.

13. That the examinations on the admissions of fellows and members shall be extended to the principles and practice of medicine, and to midwifery and pharmacy.

That the power of regulating the education of the candidates shall rest entirely with the Council.

Mr. GreEN observed that they had paid great attention to the suggestions, and all they could do at present was to promise to place the whole matter before the Council for their deliberation, and that as soon as they had determined on what course to take, an answer should be sent to the deputation They should like to know, however, while considering these arrangements, what was to become of the Apothecaries? Society, and whether the proposed alterations would not supersede the powers of that body.

Mr. BotroxLEY replied that such, no doubt, would be the result, but he had been given to understand that as soon as the questions in agitation were amicably settled, the Society was quite willing to relinquish their authority in favour of other parties.

Mr. ANcELL remarked that the efforts of the National Institute were directed with an intention to accomplish one of two things, either to procure such an alteration in the constitution of the College of Surgeons as would be acceptable to the mass of the profession, or to obtain a charter for establishing another institution for the general practitioners. It had been said out of doors, that they had not taken the proper steps to induce the Council to convert that institution into a college of general practitioners. He would, however, now publicly state, that they had used every means in their power with a view of succeeding in that object, and that they had failed; but if the Council would well consider the suggestions now produced by $\mathrm{Mr}$. Bortombex, and act upon them in framing a new constitution for the College, the Institute would immediately withdraw their application to the Crown for a charter to incorporate the general practitioners in another college.

Mr. Sorthes, of Cambridge, said that it would be very difficult for him to comply with the projected alteration, which stipulated that a certain number of fellows should recoinmend a member before he could be chosen a fellow, as there were not more than three fellows in the whole county of Cambridge. If such a law were enacted, he should be obliged to: abandon the idea of obtaining the fellowship, even if he much wished to possess it.

Mr. Smith, of St. Mary Cray, observed that it had been stated that the Act of 1815 conferred on the Apothecaries' Society all the powers which were requisite for enabling practitioners to recover at law the amount of just charges for services rendered to their patients. Previous decisions had, however, been overruled, and an instance had lately happened where a practitioner had failed to recover his demand for surgical treatment because he did not possess the diploma of the College of Surgeons. He was most anxious that such a difficulty as that should be removed. 'It could be easily done by the exertions of the Council of that College. An alteration of the law was necessary, and it was in the power of the Council to cause that alteration to be made. In con- 
clusion, he would merely remark, that if the Council should re. solve to act up to the spirit of the "suggestions" which had just been read, he should consider that they had nearly arrived at a settlement of the question of medical reform.

Dr. Webster (Dulvich), stated, that he would be most thankful to find this long agitated question set at rest. It was now in the power of the Council of that College to do much towards effecting that great object. At present the members of the medical profession were placed in a most anomalous position. There were gentlemen practising under medical degrees, diplomas, and liceuces of all kinds. He was at that time engaged in an endeavour to obtain a statistical return of the qualifications of the practitioners of the metropolis. The return is not yet complete, but he could state that there were about four hundred practitioners who held the diplomas of the College, and who were not licensed by the Apothecaries' Society; and about three hundred who possessed the licences of the Apothecaries' Society, and had not the diplomas of this College. He certainly did entertain a hope that the Council would cause some important changes to be made in the charter, and thus render the constitution of the College acceptable to the members, and to the profession generally.

Mr. Squrbe said, that the National Institute would be most thankful to find that the present interview had tencled to settle the question of medical reform, and render another institution unnecessary. He understood that the Apothecaries' Society were perfectly ready to relinquish their powers, on finding that the question was amicably settled.

Mr. Propert defended the proceedings of the Institute, and said that if the College did not take a liberal view of the present application, he understood that Mr. Bottomley would unite with them in the effort to obtain a new Coilege of General Practitioners.

The President of the College inquired the number of practitioners that the members of the deputation from the $I_{11}-$ stitute represented?

Mr. AxOELL replied that the number originally enrolled amounted to four thonsand, but when a "resolution" was passed, that cach member should pay a sovereign, the numbers were considerably reduced.

The President also inquired of Mr. Bottomley what number he represented?

Mr. ВоттомLEx, in reply, said that about two thousand signatures had been attached to their petition, all of them having been from menbers of the College; and it had certainly been numerously signed by the most respectable and influential surgeons in the different counties of England and Wales, who both then and now felt determined to effect a settlement of the question, and he ought to declare that if the Council should decline to act jnstly towards the members, they would feel themselves called upon to make a powerful effort to obtain another College; not, however, a College of General Practitioners-a most absurd title, and one which would meet with every opposition from country surgeons, but a Royal College of Medicine and Sorgery -an institution which should possess full power to confer on its members the right to practise medicine and surgery in all their departments throughout the kingdom.

The interview having terminated, and the deputation being about to withdraw, the President requested Mr. Bottomley to leave the paper which contained the "suggestions," and also to attach his signature to the document. Mr. Bottomley immediately complied with this request, and the depu. tation retired.

We understand that, subsequently to the interview, the President of the College received a letter from Mr. Bottomley, in which that gentleman stated he had inadvertently omitted from his "suggestions" that the present life members of the Council and Board of Examiners should not be disturbed in their offices by any provisions of a new charter.

MEMORIAL TO SIR GEORGE GREX, BART., FROM MANCHESTER. To the Editor of THE Lanoet.

SIr,-I am directed by the committee to send you the enclosed copy of a memorial, which has been forwarded for presentation to Sir George Grey, and to request that you will publish it in the next number of your periodical.

Your obedient servant,

Georae Bowring, Hon. Sec.

To the Right Honourable Sir George Grey, Bart., one of Her Majesty's principal Secretaries of State.

As chairman of a committee of members of the medical profession residing in Manchester and its neighbourhood, ap. pointed at a public meeting to watch the progress of the Medical Reform question, I am directed respectfully to represent to you that a statement has appeared in the public journals, to the effect that the Council of the Royal College of Surgeons of England, are about to petition the Crown for the grant of a Charter that shall amend and rectify the anomalies and deficiencies of that conceded in 1843 .

The Manchester committee, having maturely considered this reported proceeding of the Council of the College in its bearings upon medical legislation, would respectfully impress upon you the justice and expediency of withlolding all recommendation to her Majesty, in conformity with such petition, until the fellows and members at large have had the outlines of the proposed Charter submitted to them for ex. amination and discussion. The committee beg further to represent to you, that the Charter of 1843 was granted without any such previous notification; that, when published after its concession, a condemnation of its provisions, all but unani. mous came from the profession at large; and that this cir. cumstance has constituted the great obstacle to all recent attempts at medical legislation.

Finally, the commit tee would express their conviction that the grant of a Charter to the College of Surgeons, which should bring the institution into harmony with its members, who constitute the great majority of English practitioners, would remove all serious impediment to a satisfactory settle. ment of the question of Medical Reform.

(Signed, on behalf of the Committee, )

Manchester, Dec. 1849. W. Watson BeEVER, Chairman.

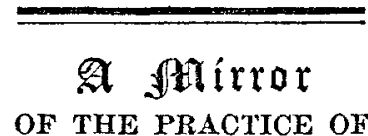

\section{MEDICINE AND SURGERY IN THE} HOSPITATS OF LONDON.

St. Thomas's Hospitad.

Extraction of a Fragment of a Catheter from the Bladder.-We have to present to our readers a case of a very remarkable description. It shows in a forcible manner the danger of em. ploying imperfect instruments, of using any force whatever in catheterism, and the advantages of the method adopted by Mr. South for the extraction of the foreign body. For the de. tails of the case we are indebted to Mr. Van Hemert, Mr. Soutli's dresser.

J. L. B-C, aged 55, a seaman, from Jersey. Admitted into Tsaac's ward on the 11th December, under the care of Mr. South; has had a stricture in the urethra several years-and has been in the habit of himself passing a bougie about once a week. Having met some friends on the 1st December, he drank freely of beer, which producing irritution and spasm of the stricture, caused partial retention of urine. The next day, being unable to relieve himself in the usual way with the bougie, he applied for assistance to a French surgeon, who attempted to pass an elastic-gum catheter, but did not succeed in getting it past the seat of stricture; on the following day a similar attempt was made, attended with the same results. On the 5 th of December, a very small and short silver catheter was used, but the bladder was not entered, and on attempting to withdraw the stylet, the straight portion of the catheter (two-thirds of the whole) came away with it, leaving the remaining third or curved portion in the urethra, where the patient distinctly felt it, and fearing it might slip into the bladder, kept quite still all day.

December 6 th.- Another medical man was consulted, who passed a bougie to ascertain if the portion of catheter was still in the urinary passage; and finding it was there, the patient was advised by his friends to come to this hospital, where he accordingly arrived on the 11th December, up to which time the patient has had no bad symptoms, but com. plains occasionally of a slight pricking pain about the peringum; urine dribbles from him, but when he attempts ho can pass it in a small stream; he was forthwith examined by Mr. South and Mr. Dixon, who found a stricture about three inches from the lips of the urethra, through which a No. 6 sound passed with a little difficulty, and entering a rather spacious false passage into the perinæum, its point could be freely moved about. Being disentangled from this, however, the instrument passed readily into the bladder, as there was not any second stricture. No foreign body could be felt in the urethra, but with very little searching in the bladder, the 